\title{
IMGD: an integrated platform supporting comparative genomics and phylogenetics of insect mitochondrial genomes
}

\author{
Wonhoon Lee ${ }^{\dagger 1,2,3}$, Jongsun Park ${ }^{\dagger 3,4,5,6}$, Jaeyoung Choi ${ }^{3,4,6}$, \\ Kyongyong Jung ${ }^{3,4}$, Bongsoo Park ${ }^{7}$, Donghan Kim ${ }^{3,4,6}$, Jaeyoung Lee ${ }^{1}$, \\ Kyohun $\mathrm{Ahn}^{4}$, Wonho Song ${ }^{4}$, Seogchan Kang ${ }^{7}$, Yong-Hwan Lee*3,4,5,6,8 \\ and Seunghwan Lee*1,2,3
}

\begin{abstract}
Address: ${ }^{1}$ Insect Biosystematics Laboratory, Seoul National University, Seoul 151-921, Korea, ${ }^{2}$ Research Institute for Agricultural and Life Sciences, Seoul National University, Seoul 151-921, Korea, ${ }^{3}$ Department of Agricultural Biotechnology, Seoul National University, Seoul 151-921, Korea, ${ }^{4}$ Fungal Bioinformatics Laboratory, Seoul National University, Seoul 151-921, Korea, ${ }^{5}$ Center for Fungal Pathogenesis, Seoul National University, Seoul 151-921, Korea, ${ }^{6}$ Center for Fungal Genetic Resources, Seoul National University, Seoul 151-921, Korea, ${ }^{7}$ Department of Plant Pathology, Penn State University, University Park, PA 16802, USA and ${ }^{8}$ Center for Agricultural Biomaterials, Seoul National University, Seoul 151-921, Korea

E-mail: Wonhoon Lee - won9@snu.ac.kr; Jongsun Park - starflr@snu.ac.kr; Jaeyoung Choi - amethyst1016@gmail.com; Kyongyong Jung - lulupon0@snu.ac.kr; Bongsoo Park - pbsfree@gmail.com; Donghan Kim - hoppang1234@gmail.com; Jaeyoung Lee - toughcd1@snu.ac.kr; Kyohun Ahn - dksrygns00@snu.ac.kr; Wonho Song - james1201@snu.ac.kr; Seogchan Kang - sxk55@psu.edu; Yong-Hwan Lee* - yonglee@snu.ac.kr; Seunghwan Lee* - seung@snu.ac.kr

*Corresponding author †Equal contributors
\end{abstract}

Published: 07 April 2009

BMC Genomics 2009, 10:148

doi: $10.1186 / 147 \mid-2164-10-148$

This article is available from: http://www.biomedcentral.com//47/-2/64//0/148

(c) 2009 Lee et al; licensee BioMed Central Ltd.

This is an Open Access article distributed under the terms of the Creative Commons Attribution License (http://creativecommons.org/licenses/by/2.0), which permits unrestricted use, distribution, and reproduction in any medium, provided the original work is properly cited.
Received: 23 October 2008

Accepted: 7 April 2009

\begin{abstract}
Background: Sequences and organization of the mitochondrial genome have been used as markers to investigate evolutionary history and relationships in many taxonomic groups. The rapidly increasing mitochondrial genome sequences from diverse insects provide ample opportunities to explore various global evolutionary questions in the superclass Hexapoda. To adequately support such questions, it is imperative to establish an informatics platform that facilitates the retrieval and utilization of available mitochondrial genome sequence data.

Results: The Insect Mitochondrial Genome Database (IMGD) is a new integrated platform that archives the mitochondrial genome sequences from 25,747 hexapod species, including 112 completely sequenced and 20 nearly completed genomes and II3,985 partially sequenced mitochondrial genomes. The Species-driven User Interface (SUI) of IMGD supports data retrieval and diverse analyses at multi-taxon levels. The Phyloviewer implemented in IMGD provides three methods for drawing phylogenetic trees and displays the resulting trees on the web. The SNP database incorporated to IMGD presents the distribution of SNPs and INDELs in the mitochondrial genomes of multiple isolates within eight species. A newly developed comparative SNU Genome Browser supports the graphical presentation and interactive interface for the identified SNPs/ INDELs.

Conclusion: The IMGD provides a solid foundation for the comparative mitochondrial genomics and phylogenetics of insects. All data and functions described here are available at the web site http://www.imgd.org/.
\end{abstract}




\section{Background}

The mitochondrial genomes of members of the superclass Hexapoda (generally referred to as the 'insects') are typically approximately 15 kilobases $(\mathrm{kb})$ in length and encode 37 genes, including 13 protein coding genes (PCGs), 2 ribosomal RNA genes (rRNAs), and 22 transfer RNA genes (tRNAs). Owing to its small size, high copy number, and relatively infrequent gene rearrangements, the mitochondrial genome has been extensively used for phylogenetic analyses [1-4]. Phylogenetic analysis based on the mitochondrial gene sequences is often limited to closely related species, due to the high rate of nucleotide substitutions. However, variations in the mitochondrial gene content and order have been utilized to elucidate evolutionary relationships among distantly-related species, on the basis of shared derived characteristics that denote the common ancestry of a given group [5].

Recent years, the number of sequenced mitochondrial genomes has been increasing fast due to rapidly growing sequencing capacity [6]. For example, more than 1,200 metazoan mitochondrial genomes have already been sequenced completely $[7,8]$. The abundance of available mitochondrial genomes has led to the development of the following web-based relational databases that are specialized for archiving the resulting data: GObase [9], AMiGA [10], Mitome [8], MamMibase [11], OGRe [7], and NCBI Organelle Genome Resources [12]. Some of these resources also provide tools for data analysis and/or viewing: MamMibase provides a web-based phylogenetic analysis tool for studying evolutionary relationships on the basis of the archived mitochondrial genomes [11] and Mitome provides a graphical mitochondrial genome browser [8]. In order to more effectively support uses of the rapidly accumulating mitochondrial genome sequences, an integrated platform that provides a diverse array of analysis tools is necessary.

Single nucleotide polymorphisms (SNPs) in the insect mitochondrial genome sequences can support fine-scale phylogenetic analyses, as illustrated in the following examples. Twenty-four biotypes of Bemisia tabaci (Hemiptera: Aleyrodidae), which could not be distinguished by morphological characteristics, were resolved [13]. SNPs in the cytochrome c oxidase subunits I (COI) locus of Aedes aegypti (Diptera: Cuclicidae) were used to differentiate four strains [14]. Based on the fully sequenced mitochondrial genomes in the genus Flustrellidra (Ctenostomata: Flustrellidridae), a SNP analysis was conducted to identify a suitable gene maker for distinguishing morphologically similar species [15].

Partially sequenced mitochondrial genes from a very large number of species also provide valuable markers for phylogenetic analysis. For example, the COI gene has been used extensively for species identification in the 'DNA barcoding' projects [16,17]. In particular, in Hexapoda, DNA barcoding projects covering multiple orders have been conducted [18-21], resulting in at least 50,000 partial sequences of COI loci in the NCBI. Because the cytochrome c oxidase subunits II (COII) locus is relatively small (approximately $600 \mathrm{bp}$ ) and can be amplified well by PCR from diverse species [22,23], many researchers have sequenced this locus, yielding more than 15,000 sequences from Hexapoda. Due to the large number of characterized insect species, sequences of these loci are an excellent resource for comprehensive phylogenetic analyses of insects; however, such data have not yet been archived in the currently available mitochondrial genome databases.

A new integrated platform named the Insect Mitochondrial Genome Database (IMGD; http://www.imgd.org/) was developed to better integrate available mitochondrial gene and genome sequences and to provide bioinformatics tools for efficient data retrieval and utilization. The IMGD archives the sequences of 112 completely sequenced and 20 nearly completed mitochondrial genome sequences, as well as partial sequences of 113,985 mitochondrial genomes (Tables 1, 2, 3) from 25,747 insect species using the standardized framework of the Comparative Fungal Genomics Platform (CFGP; http://cfgp.snu.ac.kr/) [24]. SNPs in the mitochondrial genomes of multiple isolates within eight species were identified via the SNP Analysis Platform (SAP; http://sap. snu.ac.kr/; J. Park et al., unpublished) and presented through the SNU Genome Browser (http://genomebrowser.snu.ac.kr/) [25]. BLAST [26], tRNAScan-SE [27], and mFold [28] were also incorporated into IMGD. Additionally, three phylogenetic analysis tools, including ClustalW, PHYML, and PHYLIP [29-31], were integrated into IMGD to facilitate analyses across multiple species: these tools are available through the web interface supported by Phyloviewer (http://www.phyloviewer. org/; B. Park et al., unpublished). To assist the comparison of these sequences and phylogenetic analysis within selected taxa, a new user interface, termed the Species-driven User Interface (SUI), was designed and implemented. The IMGD provides a highly integrated environment for conducting evolutionary studies of insects using their mitochondrial gene/genome sequences.

\section{Construction and content System architecture and design}

The IMGD consists of three integrated layers: i) a standardized data warehouse that is supported by CFGP [24], ii) the middleware platform for the integration of various bioinformatics programs via standardized 
Table I: List of the number of mitochondrial sequences in Hexapoda archived in the IMGD

\begin{tabular}{|c|c|c|c|c|}
\hline Order & Species & $\mathbf{C G}^{\mathrm{a}}$ & $\mathbf{N G}{ }^{\mathbf{b}}$ & $\mathbf{P G}^{\mathrm{c}}$ \\
\hline Archaeognatha & 10 & 4 & 0 & 15 \\
\hline Blattaria & 274 & I & 0 & 991 \\
\hline Coleoptera & 6,594 & 8 & 4 & 25,783 \\
\hline Collembola & 133 & 6 & 2 & 947 \\
\hline Dermaptera & 35 & 0 & 0 & 63 \\
\hline Diplura & 10 & 3 & 0 & 24 \\
\hline Diptera & 3,846 & 24 & 2 & 26,982 \\
\hline Embioptera & 14 & 0 & 0 & 26 \\
\hline Ephemeroptera & 288 & I & 0 & 742 \\
\hline Grylloblattodea & 17 & 0 & 1 & 113 \\
\hline Hemiptera & $|, 85|$ & 20 & 5 & 7,299 \\
\hline Hymenoptera & 4,144 & 3 & 2 & 14,737 \\
\hline Isoptera & 647 & 7 & 0 & 2,842 \\
\hline Lepidoptera & 4,556 & 7 & 2 & 19,380 \\
\hline Mantodea & 188 & 1 & 0 & 717 \\
\hline Mantophasmatodea & 17 & 1 & 0 & 194 \\
\hline Mecoptera & 61 & 0 & 0 & $14 \mid$ \\
\hline Megaloptera & 7 & 2 & 0 & 409 \\
\hline Neuroptera & 143 & 2 & 0 & 437 \\
\hline Odonata & 525 & 0 & 1 & $\mathrm{I}, 734$ \\
\hline Orthoptera & 919 & 14 & 0 & 4,744 \\
\hline Phasmatodea & 64 & 0 & I & 482 \\
\hline Phthiraptera & 527 & 3 & 0 & 2,155 \\
\hline Plecoptera & 184 & I & 0 & 529 \\
\hline Protura & 2 & 0 & 0 & 6 \\
\hline Psocoptera & 121 & 1 & 0 & 338 \\
\hline Raphidioptera & 4 & 0 & 0 & 5 \\
\hline Siphonaptera & 35 & 0 & 0 & 134 \\
\hline Strepsiptera & 6 & 0 & 0 & 7 \\
\hline Thysanoptera & 154 & I & 0 & 857 \\
\hline Trichoptera & 343 & 0 & 0 & 1,100 \\
\hline Zoraptera & 1 & 0 & 0 & 2 \\
\hline Zygentoma & 27 & 2 & 0 & 50 \\
\hline Total & 25,747 & 112 & 20 & 113,985 \\
\hline
\end{tabular}

${ }^{\mathrm{a} C}$ Completely sequenced mitochondrial genome, ${ }^{\mathrm{b}} \mathrm{Nearly}$ completely sequenced mitochondrial genome, and 'Partially sequenced mitochondrial gene sequences

input and output interfaces, and iii) the web-based user interface, including the Species-driven User Interface (Figure 1A). In order to support the efficient archiving and analysis of a very large number of heterogeneous mitochondrial gene sequences (Table 2 and Table 3), a standardized structure for sequence data was required: this requirement was solved using CFGP [24], which has demonstrated its reliability and expandability via several published databases [32-37].

To support phylogenetic studies using the archived hexapod mitochondrial sequences, ClustalW (Version 1.83), PHYLIP (Version 3.68), and PHYML (Version 3.0) [29-31], which support the Neighbour Joining (NJ), Maximum Parsimony (MP), and Maximum Likelihood (ML) methods, respectively, were incorporated. The visualization and management of the resulting phylogenetic data are supported by the Phyloviewer (http:// www.phyloviewer.org/), which has been successfully employed in other platforms [24,34,35]. BLAST [26] was integrated with datasets containing mitochondrial gene sequences and hexapod taxonomy information, and tRNAscan-SE (Version 1.23) [27] and mFold (Version 3.2) [28] were embedded to allow for the display and comparison of secondary structures of tRNAs and anticodon sequences.

The user interface of IMGD provides the Mitochondrial Genome Browser, which is founded on the SNU Genome Browser (http://genomebrowser.snu.ac.kr/) [25], to support the browsing and comparison of mitochondrial genome sequences in both the text and graphical forms via an interactive interface, and the Partial Sequence Browser to allow for the browsing of partially sequenced mitochondrial sequences. The IMGD also provides the Object Browser, which can collect and move selected sequences in IMGD into the Favorite, a personalized virtual storage space, for further data analyses using the analysis tools in both IMGD and CFGP [24]. The IMGD archives sequences and taxonomical information from more than 25,000 hexapod species. To facilitate the organization and presentation of data according to the taxonomic position/grouping of the species of origin, a new interface named the Species-driven User Interface (SUI) was designed and implemented in IMGD.

\section{Pipeline for updating the IMGD data warehouse}

To support periodic updating of the IMGD data warehouse, the following automatic analysis pipeline was developed (Figure 1B). In the first step, completely and partially sequenced mitochondrial genome sequences are downloaded from NCBI using proper keywords after filtering out unpublished sequences. The downloaded sequences are subsequently filtered using several stop words in order to remove non-mitochondrial sequences. Secondly, the mitochondrial genome parsers, which were written in PERL, parse and store the filtered data into the data warehouse. Thirdly, adjoined stop codons at the 3'end of the PCGs that overlap with neighboring PCGs or tRNAs in the mitochondrial genome [38], are manually checked to determine whether they are correct or not. Lastly, certain properties of the genome, including the CG content, AT skew, and codon usage, are calculated for graphical representations via SNU Genome Browser, and various cache tables are updated. In the final step, BLAST datasets, tRNA annotation information via both tRNAScan-SE [27] and mFold [28], and SNP databases are updated. 
Table 2: List of 56 whole mitochondrial genomes of hexapod species (Part I. 52 holometabolous species) archived in IMGD

\begin{tabular}{|c|c|c|c|c|c|c|}
\hline Order & Species & Size (bp) & GC (\%) & PCGs & tRNAs & rRNAs \\
\hline Coleoptera & Chaetosoma scaritides* & $|5,5| \mid$ & 20.96 & 13 & 22 & 2 \\
\hline Coleoptera & Crioceris duodecimpunctata & 15,880 & 23.11 & 13 & 22 & 2 \\
\hline Coleoptera & Cyphon sp. BT00I2 & 15,919 & 24.83 & 13 & 22 & 2 \\
\hline Coleoptera & Priasilpha obscura* & 16,603 & 23.49 & 13 & 22 & 2 \\
\hline Coleoptera & Pyrocoelia rufa & 17,739 & 22.59 & 13 & 22 & 2 \\
\hline Coleoptera & Pyrophorus divergens & 16,120 & 30.56 & 13 & 22 & 2 \\
\hline Coleoptera & Rhagophthalmus lufengensis & 15,982 & 20.37 & 13 & 22 & 2 \\
\hline Coleoptera & Rhagophthalmus ohbai & 15,704 & 20.85 & 13 & 19 & 2 \\
\hline Coleoptera & Sphaerius sp. BT0074* & $|5,12|$ & 19.28 & 13 & 22 & 2 \\
\hline Coleoptera & Tetraphalerus bruchi & 15,689 & 33.01 & 13 & 22 & 2 \\
\hline Coleoptera & Trachypachus holmbergi* & 15,722 & 20.54 & 13 & 22 & 2 \\
\hline Coleoptera & Tribolium castaneum & $|5,88|$ & 28.32 & 13 & 22 & 2 \\
\hline Diptera & Anopheles funestus* & 15,354 & 21.84 & 7 & 22 & 2 \\
\hline Diptera & Anopheles gambiae & 15,363 & 22.44 & 13 & 22 & 2 \\
\hline Diptera & Anopheles quadrimaculatus A Orlando & 15,455 & 22.64 & 13 & 22 & 2 \\
\hline Diptera & Bactrocera oleae Italy & 15,815 & 27.41 & 13 & 22 & 2 \\
\hline Diptera & Bactrocera oleae Portugal & 15,815 & 27.37 & 13 & 22 & 2 \\
\hline Diptera & Ceratitis capitata & 15,980 & 22.52 & 13 & 22 & 2 \\
\hline Diptera & Chrysomya putoria & 15,837 & 23.30 & 13 & 23 & 2 \\
\hline Diptera & Cochliomyia hominivorax & 16,022 & 23.10 & 13 & 22 & 2 \\
\hline Diptera & Cydistomyia duplonotata & 16,247 & 22.07 & 13 & 23 & 2 \\
\hline Diptera & Drosophila ananassae & 14,920 & 22.59 & 13 & 22 & 2 \\
\hline Diptera & Drosophila erecta & 14,952 & 22.77 & 13 & 22 & 2 \\
\hline Diptera & Drosophila grimshawi & 14,874 & 23.24 & 13 & 22 & 2 \\
\hline Diptera & Drosophila mauritiana G52 & 14,964 & 22.29 & 13 & 22 & 2 \\
\hline Diptera & Drosophila melanogaster & 19,517 & 17.84 & 13 & 22 & 2 \\
\hline Diptera & Drosophila mojavensis & 14,904 & 23.54 & 13 & 22 & 2 \\
\hline Diptera & Drosophila simulans KY007 & 14,946 & 22.33 & 13 & 22 & 2 \\
\hline Diptera & Drosophila simulans KY045 & 14,946 & 22.36 & 13 & 22 & 2 \\
\hline Diptera & Drosophila simulans KY20I & 14,946 & 22.32 & 13 & 22 & 2 \\
\hline Diptera & Drosophila simulans KY2I5 & 14,946 & 22.33 & 13 & 22 & 2 \\
\hline Diptera & Drosophila persimilis & 14,930 & 22.70 & 13 & 22 & 2 \\
\hline Diptera & Drosophila virilis & 14,949 & 23.25 & 13 & 22 & 2 \\
\hline Diptera & Drosophila willistoni & $14,9 \mid 5$ & 22.76 & 13 & 22 & 2 \\
\hline Diptera & Drosophila yakuba & 16,019 & 21.41 & 13 & 22 & 2 \\
\hline Diptera & Simosyrphus grandicornis & $|6,14|$ & 19.16 & 13 & 22 & 2 \\
\hline Diptera & Stomoxys calcitrans* & 16,790 & 21.07 & 12 & 23 & 2 \\
\hline Diptera & Trichophthalma punctata & 16,396 & 26.04 & 13 & 21 & 2 \\
\hline Hymenoptera & Abispa ephippium & 16,953 & 19.39 & 13 & 26 & 2 \\
\hline Hymenoptera & Apis mellifera & 16,343 & 15.14 & 13 & 22 & 2 \\
\hline Hymenoptera & Bombus ignites & 16,434 & 13.22 & 13 & 22 & 2 \\
\hline Hymenoptera & Vanhornia eucnemidarum* & 16,574 & 19.86 & 13 & 18 & 2 \\
\hline Hymenoptera & Xenos vesparum* & 14,519 & 20.68 & 13 & 23 & I \\
\hline Lepidoptera & Adoxophyes honmai & 15,680 & |9.61 & 13 & 22 & 2 \\
\hline Lepidoptera & Bombyx mandarina & 15,928 & 18.32 & 13 & 22 & 2 \\
\hline Lepidoptera & Bombyx mori C-108 & 15,656 & 18.64 & 13 & 22 & 2 \\
\hline Lepidoptera & Coreana raphaelis & $15,3 \mid 4$ & 17.34 & 13 & 23 & 2 \\
\hline Lepidoptera & Manduca sexta & 15,516 & $|8.2|$ & 13 & 23 & 2 \\
\hline Lepidoptera & Ochrogaster lunifer & 15,593 & 22.16 & 13 & 22 & 2 \\
\hline Lepidoptera & Ostrinia furnacalis* & 14,536 & 19.62 & 13 & 22 & 2 \\
\hline Lepidoptera & Ostrinia nubilalis* & 14,535 & 19.84 & 13 & 22 & 2 \\
\hline Lepidoptera & Saturnia boisduvalii & 15,360 & 19.38 & 13 & 22 & 2 \\
\hline Megaloptera & Corydalus cornutus & 15,687 & 25.10 & 13 & 22 & 2 \\
\hline Megaloptera & Protohermes concolorus & $|5,85|$ & 24.17 & 13 & 22 & 2 \\
\hline Neuroptera & Ascaloptynx appendiculatus & 15,877 & 24.43 & 13 & 22 & 2 \\
\hline Neuroptera & Polystoechotes punctatus & 16,036 & 21.04 & 12 & 22 & 2 \\
\hline
\end{tabular}

*Nearly completely sequenced mitochondrial genome. 
Table 3: List of 76 whole mitochondrial genomes of hexapod species (Part II. 73 species excluding holometabolous orders) archived in IMGD

\begin{tabular}{|c|c|c|c|c|c|c|}
\hline Order & Species & Size (bp) & GC (\%) & PCGs & tRNAs & rRNAs \\
\hline Archaeognatha & Nesomachilis australica & 15,474 & 31.17 & 13 & 21 & 2 \\
\hline Archaeognatha & Pedetontus silvestrii & 15,879 & 25.66 & 13 & 22 & 2 \\
\hline Archaeognatha & Petrobius brevistylis & 15,698 & 32.12 & 13 & 22 & 2 \\
\hline Archaeognatha & Trigoniophthalmus alternatus & 16,197 & 28.59 & 13 & 22 & 2 \\
\hline Zygentoma & Thermobia domestica & 15,152 & 33.01 & 13 & 22 & 2 \\
\hline Zygentoma & Tricholepidion gertschi & 15,267 & 31.40 & 13 & 22 & 2 \\
\hline Collembola & Cryptopygus antarcticus & 15,297 & 29.10 & 13 & 23 & 2 \\
\hline Collembola & Gomphiocephalus hodgsoni & 15,075 & 25.92 & 13 & 22 & 2 \\
\hline Collembola & Friesea grisea & 15,425 & 27.73 & 13 & 22 & 2 \\
\hline Collembola & Onychiurus orientalis* & 12,984 & 30.89 & 13 & 20 & I \\
\hline Collembola & Orchesella villosa & 14,924 & 27.82 & 13 & 22 & 2 \\
\hline Collembola & Podura aquatica* & 13,809 & 34.21 & 13 & 20 & I \\
\hline Collembola & Sminthurus viridis & $14,8 \mid 7$ & 30.56 & 13 & 22 & 2 \\
\hline Collembola & Tetrodontophora bielanensis & 15,455 & 27.32 & 13 & 22 & 2 \\
\hline Diplura & Campodea fragilis & 14,965 & 27.44 & 13 & 22 & 2 \\
\hline Diplura & Campodea lubbocki & 14,974 & 25.19 & 13 & 22 & 2 \\
\hline Diplura & Japyx solifugus & 15,785 & 35.18 & 13 & 22 & 2 \\
\hline Ephemeroptera & Parafronurus youi & $|5,48|$ & 33.62 & 13 & 23 & 2 \\
\hline Odonata & Orthetrum triangulare melania* & 14,033 & 26.09 & 13 & 19 & 2 \\
\hline Grylloblattodea & Grylloblatta sculleni* & 15,595 & 29.71 & 12 & 19 & 2 \\
\hline Blattaria & Periplaneta fuliginosa & 14,996 & 24.85 & 13 & 22 & 2 \\
\hline Isoptera & Reticulitermes flavipes ISI3 & 16,565 & 33.82 & 13 & 22 & 2 \\
\hline Isoptera & Reticulitermes flavipes IS57 & 16,569 & 33.76 & 13 & 22 & 2 \\
\hline Isoptera & Reticulitermes flavipes IS58 & 16,567 & 33.78 & 13 & 22 & 2 \\
\hline Isoptera & Reticulitermes hageni & 16,590 & 34.45 & 13 & 22 & 2 \\
\hline Isoptera & Reticulitermes santonensis IS54 & 16,567 & 33.91 & 13 & 22 & 2 \\
\hline Isoptera & Reticulitermes virginicus IS59 & $16,5 \mid 3$ & 34.12 & 13 & 22 & 2 \\
\hline Isoptera & Reticulitermes virginicus IS60 & 15,966 & 34.37 & 13 & 22 & 2 \\
\hline Mantodea & Tamolanica tamolana & 16,055 & 24.73 & 13 & 22 & 2 \\
\hline Mantophasmatodea & Sclerophasma paresisense & 15,500 & 24.94 & 13 & 22 & 2 \\
\hline Orthoptera & Acrida willemsei & $|5,60|$ & 23.78 & 13 & 22 & 2 \\
\hline Orthoptera & Anabrus simplex & 15,766 & 30.56 & 13 & 22 & 2 \\
\hline Orthoptera & Calliptamus italicus & 15,675 & 26.74 & 13 & 22 & 2 \\
\hline Orthoptera & Chorthippus chinensis & 15,599 & 24.89 & 13 & 22 & 2 \\
\hline Orthoptera & Deracantha onos & 15,650 & 30.76 & 13 & 22 & 2 \\
\hline Orthoptera & Gryllotalpa orientalis & $|5,52|$ & 29.51 & 13 & 22 & 2 \\
\hline Orthoptera & Gryllotalpa pluvialis & 15,525 & 27.80 & 13 & 22 & 2 \\
\hline Orthoptera & Locusta migratoria & 15,722 & 24.67 & 13 & 22 & 2 \\
\hline Orthoptera & Myrmecophilus manni & 15,323 & 29.82 & 13 & 22 & 2 \\
\hline Orthoptera & Oxya chinensis & 15,443 & 24.11 & 13 & 22 & 2 \\
\hline Orthoptera & Ruspolia dubia & $|4,97|$ & 29.14 & 13 & 22 & 2 \\
\hline Orthoptera & Gastrimargus marmoratus & 15,924 & 24.82 & 13 & 22 & 2 \\
\hline Orthoptera & Gampsocleis gratiosa & 15,929 & 34.69 & 13 & 22 & 2 \\
\hline Orthoptera & Troglophilus neglectus & 15,810 & 26.63 & 13 & 23 & 2 \\
\hline Phasmatodea & Timema californicum* & 14,387 & 27.86 & 13 & 19 & 1 \\
\hline Plecoptera & Pteronarcys princeps & 16,004 & 28.54 & 13 & 22 & 2 \\
\hline Hemiptera & Aeschyntelus notatus* & 14,532 & 24.29 & 13 & 22 & 2 \\
\hline Hemiptera & Aleurochiton aceris & 15,388 & 22.10 & 13 & 21 & 2 \\
\hline Hemiptera & Aleurodicus dugesii & 15,723 & 13.67 & 13 & 20 & 2 \\
\hline Hemiptera & Bemisia tabaci & 15,322 & 24.32 & 13 & 22 & 2 \\
\hline
\end{tabular}


Table 3: List of 76 whole mitochondrial genomes of hexapod species (Part II. 73 species excluding holometabolous orders) archived in IMGD (Continued)

\begin{tabular}{|c|c|c|c|c|c|c|}
\hline Hemiptera & Coptosoma bifaria & 16,179 & 28.67 & 13 & 22 & 2 \\
\hline Hemiptera & Dysdercus cingulatus & 16,249 & 22.31 & 13 & 22 & 2 \\
\hline Hemiptera & Geocoris pallidipennis* & 14,592 & 24.14 & 13 & 22 & 2 \\
\hline Hemiptera & Hydaropsis longirostris & $|6,52|$ & 24.54 & 13 & 22 & 2 \\
\hline Hemiptera & Macroscytus subaeneus* & 14,620 & 26.21 & 13 & 22 & 2 \\
\hline Hemiptera & Malcus inconspicuus & 15,575 & 22.20 & 13 & 22 & 2 \\
\hline Hemiptera & Neomaskellia andropogonis & 14,496 & 18.73 & 13 & 18 & 2 \\
\hline Hemiptera & Neuroctenus parus & 15,354 & 31.14 & 13 & 22 & 2 \\
\hline Hemiptera & Nezara viridula & 16,889 & 23.12 & 13 & 22 & 2 \\
\hline Hemiptera & Orius niger* & 14,494 & 23.47 & 13 & 22 & 2 \\
\hline Hemiptera & Pachypsylla venusta & $|4,7| \mid$ & 25.00 & 13 & 22 & 2 \\
\hline Hemiptera & Phaenacantha marcida* & 14,540 & 26.54 & 13 & 22 & 2 \\
\hline Hemiptera & Philaenus spumarius & 16,324 & 23.01 & 13 & 22 & 2 \\
\hline Hemiptera & Physopelta gutta & 14,935 & 25.49 & 13 & 22 & 2 \\
\hline Hemiptera & Riptortus pedestris & 17,191 & 23.41 & 13 & 22 & 2 \\
\hline Hemiptera & Saldula arsenjevi & 15,324 & 25.39 & 13 & 22 & 2 \\
\hline Hemiptera & Schizaphis graminum & $|5,72|$ & 16.06 & 13 & 22 & 2 \\
\hline Hemiptera & Tetraleurodes acacia & 15,080 & 28.02 & 13 & 19 & 2 \\
\hline Hemiptera & Trialeurodes vaporariorum & $|8,4| 4$ & 27.70 & 13 & 22 & 2 \\
\hline Hemiptera & Triatoma dimidiate & 17,019 & 30.43 & 13 & 22 & 2 \\
\hline Hemiptera & Yemmalysus parallelus & 15,747 & 22.82 & 13 & 22 & 2 \\
\hline Phthiraptera & Bothriometopus macrocnemis & 15,564 & 29.20 & 13 & 25 & 2 \\
\hline Phthiraptera & Campanulotes bidentatus & 14,804 & 29.88 & 13 & 22 & 2 \\
\hline Phthiraptera & Heterodoxus macropus & 14,670 & 20.72 & 13 & 22 & 2 \\
\hline Psocoptera & Lepidopsocid sp. RS200I & 16,924 & 20.98 & 13 & 22 & 2 \\
\hline Thysanoptera & Thrips imaginis & 15,407 & 23.43 & 13 & 23 & 2 \\
\hline
\end{tabular}

*Nearly completely sequenced mitochondrial genome.

\section{Taxonomic origins of the sequences data archived in IMGD}

The IMGD archives 132 hexapod mitochondrial genomes and 113,985 GenBank accessions of partially sequenced mitochondrial genes, consisting of 102,430 PCGs, 19,452 rRNAs, and 17,944 tRNAs, from 25,747 species belonging to 33 orders (Table 1). More than 10,000 mitochondrial gene sequences were derived from $>1,000$ species in the orders Coleoptera, Lepidoptera, Hymenoptera, and Diptera. In particular, members of Diptera and Coleoptera account for 26 (20.00\%) and 12 (9.23\%) mitochondrial genomes, respectively, reflecting active researches on these orders $[39,40]$. In contrast, the following 13 orders (39.39\%) are represented only by less than 50 species in total: Dermaptera, Siphonaptera, Zygentoma, Grylloblattodea, Mantophasmatodea, Embioptera, Diplura, Archaeognatha, Strepsiptera, Megaloptera, Raphidioptera, Protura, and Zoraptera (Table 1). The underrepresentation of mitochondrial gene sequences from many orders suggests that to adequately support the analysis of evolutionary relationships within the Hexapoda, these underrepresented orders require more attention.

\section{Notable features in hexapod mitochondrial genomes}

The genome size, GC content, and the number of PCGs, tRNAs, and rRNAs of the 132 mitochondrial genomes archived in IMGD (Table 2 and Table 3) were assessed (Figure 2). The GC content ranges from $13.22 \%$ to $35.18 \%$ with an average of $25.09 \%$, showing the association at the order level (Figure 2A). The genome sizes vary from 12,984 bp to $19,517 \mathrm{bp}$, with an average of 15,617 bp with no clear correlation at any taxon levels (Figure 2B). Analyses of gene order in the 112 completely sequenced mitochondrial genomes revealed several interesting features. In 42 genomes (37.50\%), which represent 12 orders, at least 222 gene insertions, deletions, inversions, and translocations were identified relative to the gene arrangement of the ancestral insect Drosophila yakuba $[3,41]$ (Lee et al., in preparation). Gene translocations and inversions were detected in the following 12 orders: Collembola, Archaeognatha, Zygentoma, Hemiptera, Thysanoptera, Psocoptera, Phthiraptera, Neuroptera, Hymenoptera, Orthoptera, Lepidoptera, and Diptera. Gene insertions and deletions were detected in Collembola, Ephemeroptera, Orthoptera, Hemiptera, Phthiraptera, Diptera, and Lepidoptera. 


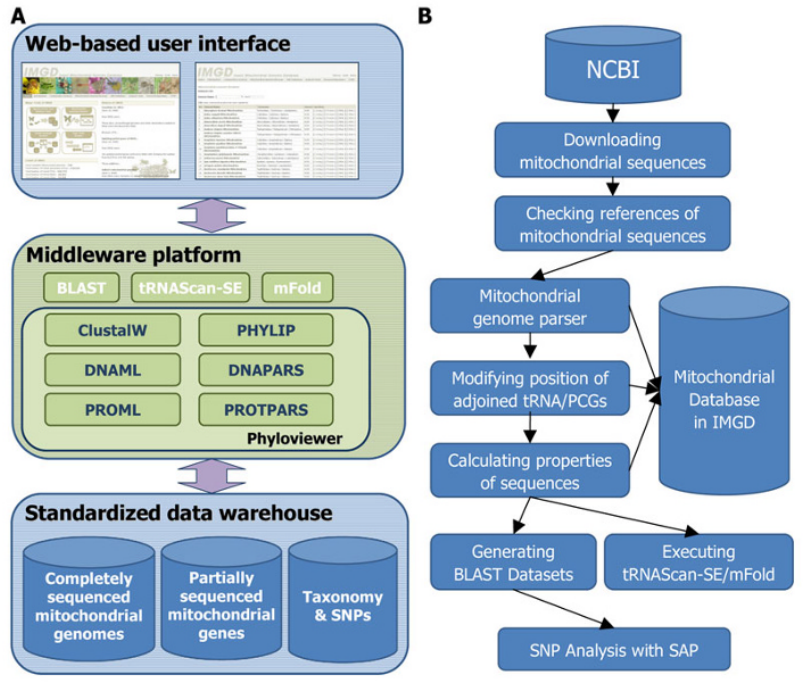

Figure I

The system architecture and pipeline of IMGD.

(A) Each rectangular box shows three layers. In the standardized data warehouse, diverse databases are placed. The middleware platform manages not only BLAST, tRNAScan-SE, and mFold but also six phylogenetic tools managed by Phyloviewer (http://www.phyloviewer.org/). The web-based user interface supports browsing all information deposited in IMGD. (B) The pipeline for archiving hexapod mitochondrial sequences and calculating their properties was presented as a flowchart diagram.

\section{Examples of phylogenetic analyses results using insectmitochondrial genomes}

To demonstrate the utility of IMGD for phylogenetic analysis and also to test the system, many phylogenetic analyses using the data archived in IMGD have been conducted (e.g., Figure 3). Figure 3A shows an ML phylogenetic tree based on 19 completely sequenced and 5 nearly completed mitochondrial genomes in the order Hemiptera, which clearly shows two major suborder clades (Sternorrhyncha + Auchenorrhyncha and Heteroptera). The MP trees based on the COI gene sequences (Figure $3 \mathrm{~B}$ and $3 \mathrm{C}$ ) revealed more comprehensive phylogenetic relationships than those derived from previous studies in the orders Phthiraptera [42-44] and Mantophasmatodea $[45,46]$.

\section{Single Nucleotide Polymorphisms among}

\section{9 insect mitochondrial genomes}

Single nucleotide polymorphisms (SNPs) in eight species with more than one mitochondrial genome having been sequenced (Table 4), were analyzed via the SNP Analysis Platform (http://sap.snu.ac.kr/), which is based on BLAST. A total of 856 SNPs and 30 insertion and deletions (INDELs) were identified (Table 4) from $187 \mathrm{kbp}$ of aligned mitochondrial genome sequences (6 pair-wise comparisons of mitochondrial genomes). Among these, 621 SNPs (72.55\%) were identified in 13 PCGs and designated as cSNPs. Figure 4 shows the average number of cSNPs in each species, order and PCG. Bactrocera oleae (BO), Drosophila simulans (DS), and Reticulitermes flavipes (RF) exhibited the highest frequency of cSNPs, similar to the results from previous genome sequence analyses [47-49]. Among the 13 PCGs, the COI, NADH dehydrogenase subunit 4 (ND4), and/or $\mathrm{NADH}$ dehydrogenase subunit 5 (ND5) genes showed the highest frequency of SNPs in Diptera (COI and ND5) and Isoptera (cytochrome b, ND4, and ND5) (Figure 4). These regions can serve as potential molecular markers in population genetic studies of these three orders.

\section{Utilities and discussion}

\section{Species-driven User Interface (SUI)}

The SUI of IMGD supports efficient data retrieval and analysis at multi-taxon levels. The SUI was developed using Ajax technology, which supports faster performance than other methods (e.g. JavaScript and Java applets). The SUI helps the users of IMGD search hexapod taxa using the 'Species search' and supports the addition and deletion of selected insect species via the 'Species cart' function, which is similar to the cart functions commonly used on online shopping sites (Figure 3). After placing the taxa of interest in the cart, they can be analyzed in the following ways: i) downloading nucleotide and protein sequences and/or storing them into the Favorite with various options, ii) comparing gene orders, GC content/AT skew, codon usage and position among mitochondrial genomes, iii) displaying tRNA secondary structures predicted by tRNAScan-SE [27] and mFold [28], iv) executing ClustalW for multiple sequence alignment and calculating phylogenetic trees based on three methods, including NJ, MP, and ML, with a bootstrapping option, v) executing a BLAST search against the selected taxa, and vi) saving species information into the Favorite for future analyses (Figure 5). Since SUI was designed using a standardized application programming interface (API), additional programs can be easily incorporated into SUI.

\section{Gene order browser for graphical presentation of elements on the mitochondrial genome}

Gene rearrangement events in the mitochondrial genomes can be used for tracing the evolutionary history of the mitochondrial genomes in Hexapoda (Lee et al., in preparation). The gene order browser implemented in IMGD was designed for efficient graphical presentation 


\section{A. GC content}

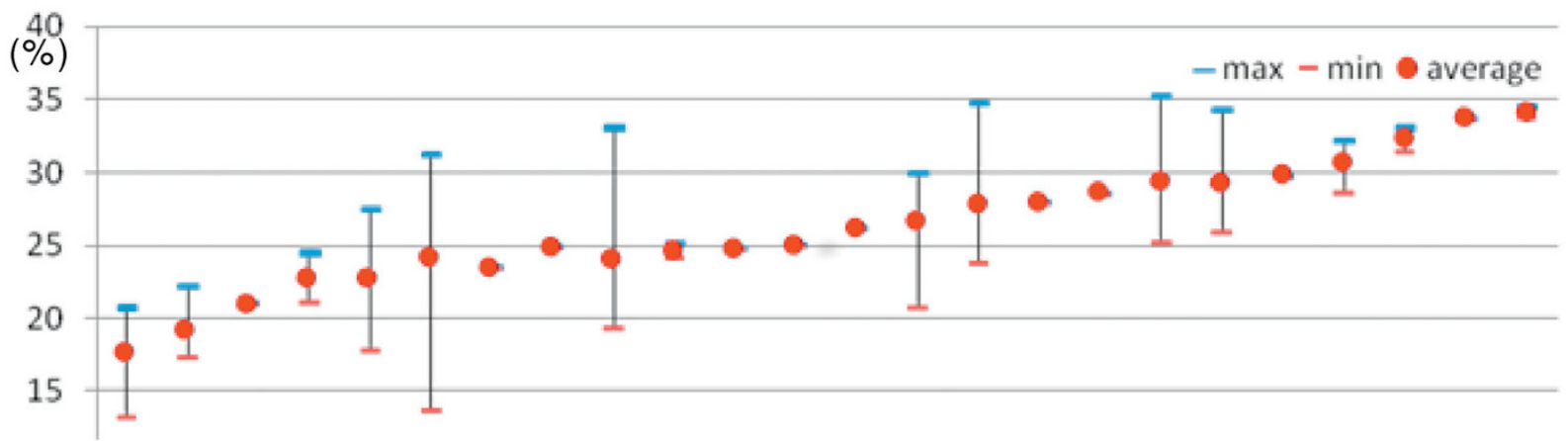

\section{B. Genome size}

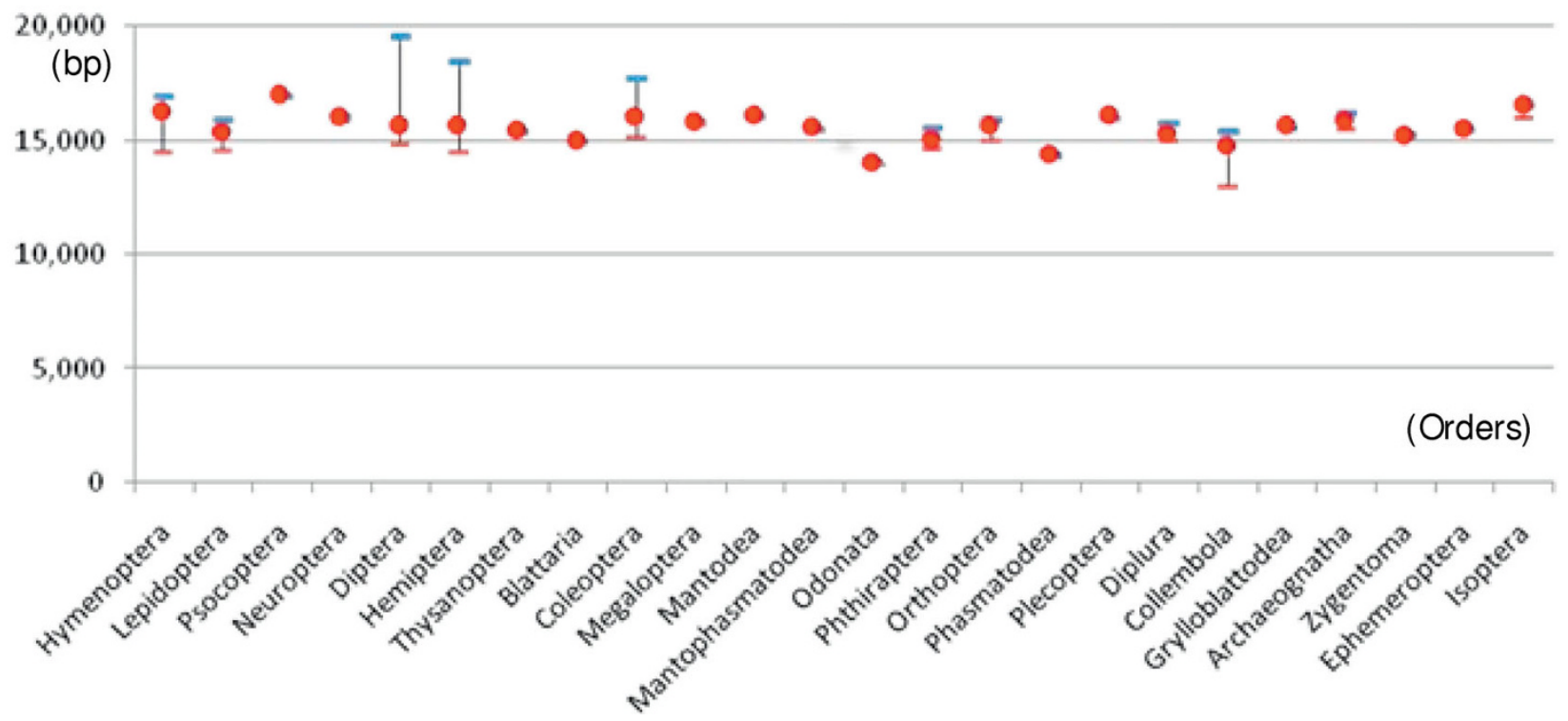

Figure 2

Estimates of the GC content and genome size of the 132 hexapod mitochondrial genomes. (A) The ranges of the GC content in the nearly completely and the completely sequenced mitochondrial genomes are shown. The closed red circle indicates the average GC content, and the blue and red bars present the maximum and minimum GC contents, respectively. (B) The distribution of mitochondrial genome sizes in different hexapod orders is shown. The closed red circle indicates the average mitochondrial genome size and the blue and red bars present the largest and smallest genome sizes, respectively (see also Table 2 and Table 3).

of PCGs, tRNAs, and rRNAs in the mitochondrial genome. To display different features on the genome graphically, the browser uses three different colors for PCGs, tRNAs, and rRNAs, and presents names of individual units (Figure 6). Moreover, the gene order browser displays the gene organizations using a specific gene as the start site for the linear genome diagrams regardless of the arbitrary start position given to individual mitochondrial genomes. Users can choose the number of mitochondrial genomes to be displayed by selecting them via SUI.

\section{Integrated platform for phylogenetic analyses supported by Phyloviewer}

The Phyloviewer (http://www.phyloviewer.org/) provides four phylogenetic analysis programs (ClustalW, DNAPARS/ PROTPARS, DNAML/PROML, and PHYML [29-31]) via a common interface to support phylogenetic studies based on the mitochondrial gene/genome sequences archived in IMGD. Three different methods of drawing phylogenetic trees (NJ, MP, and ML) are currently available. In addition, the interactive capability of graphical presentation of sequence alignments and selecting and storing all sequences 


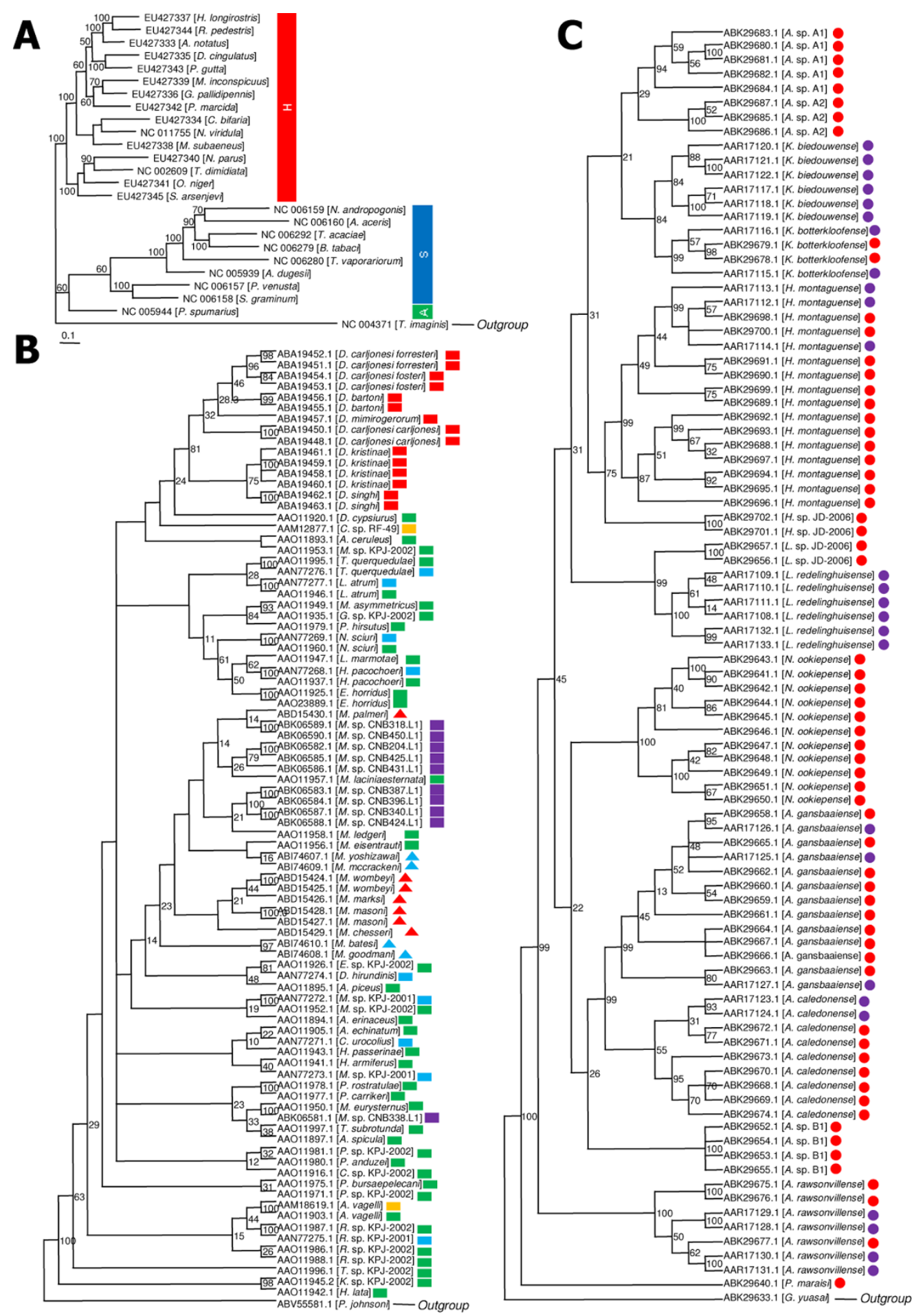

Figure 3

Examples of phylogenetic analyses conducted using data and tools in IMGD. (A) ML tree of the 24 Hemipteran species ( 19 completely and 5 nearly completed mitochondrial genomes) with Thrips imaginis (Thysanoptera) as an outgroup was constructed using DNAML. S, Sternorrhyncha; A, Auchenorrhyncha; H, Heteroptera. (B) MP tree built based on $88 \mathrm{COI}$ sequences from 70 Phthirapteran species using DNAPARS, is shown. Ptycta johnsoni (Psocoptera) was used as an outgroup. The blue square indicates the sequences originated from Johnson and Whiting (2002) [42]; green square, Johnson et al. (2003) [43]; blue triangle, Price and Johnson (2006) [44]; red, violet and yellow squares, and red triangle present unpublished mitochondrial gene sequences. (C) MP tree using $90 \mathrm{COl}$ sequences from 14 Mantophasmatodean species, with Galloisiana yuasai (Grylloblattodea) as an outgroup, was drawn using DNAPARS. The red circle indicates the mitochondrial sequences reported by Damgaard et al. (2008) [46] and violet circle presents the sequences from the study of Klass et al. (2003) [45]. The numbers on individual nodes of the trees in $A, B$, and $C$ indicate bootstrap values with 10, 100, and 100 repeats, respectively, and the names of the species used and NCBI accession numbers are shown at the end of individual branches. 
Table 4: List of mitochondrial genome comparisons for SNP analysis

\begin{tabular}{|c|c|c|c|c|c|}
\hline Order & Source/Target Species & Size (bp) & Aligned (bp) & SNPs & INDELs \\
\hline \multirow[t]{4}{*}{ Diptera } & $\begin{array}{l}\text { Bactrocera oleae Italy vs } \\
\text { Bactrocera oleae portugal }\end{array}$ & $\begin{array}{l}15,815 \\
15,815\end{array}$ & $\begin{array}{l}15,815 \\
15,815\end{array}$ & 31 & 0 \\
\hline & $\begin{array}{l}\text { Drosophila simulans KY007 } \\
\text { Drosophila simulans KY045 }\end{array}$ & $\begin{array}{l}14,946 \\
14,946\end{array}$ & $\begin{array}{l}14,946 \\
14,946\end{array}$ & 25 & 2 \\
\hline & $\begin{array}{l}\text { Drosophila simulans } \mathrm{KY} 007 \\
\text { Drosophila simulans } \mathrm{KY} 20 \mathrm{I}\end{array}$ & $\begin{array}{l}14,946 \\
14,946\end{array}$ & $\begin{array}{l}14,946 \\
14,946\end{array}$ & 17 & 2 \\
\hline & $\begin{array}{l}\text { Drosophila simulans } \mathrm{KY} 007 \\
\text { Drosophila simulans } \mathrm{KY} 2 \mathrm{I} 5\end{array}$ & $\begin{array}{l}14,946 \\
14,946\end{array}$ & $\begin{array}{l}14,946 \\
14,946\end{array}$ & 6 & 0 \\
\hline \multirow[t]{2}{*}{ Isoptera } & $\begin{array}{l}\text { Reticulitermes flavipes ISI3 vs } \\
\text { Reticulitermes flavipes IS57 }\end{array}$ & $\begin{array}{l}16,565 \\
16,569\end{array}$ & $\begin{array}{l}16,561 \\
16,565\end{array}$ & 393 & 14 \\
\hline & $\begin{array}{l}\text { Reticulitermes flavipes ISI } 3 \text { vs } \\
\text { Reticulitermes flavipes IS58 }\end{array}$ & $\begin{array}{l}16,565 \\
16,567\end{array}$ & $\begin{array}{l}16,561 \\
16,563\end{array}$ & 384 & 12 \\
\hline Total & 6 pair-wise comparisons & 187,572 & 187,556 & 856 & 30 \\
\hline
\end{tabular}

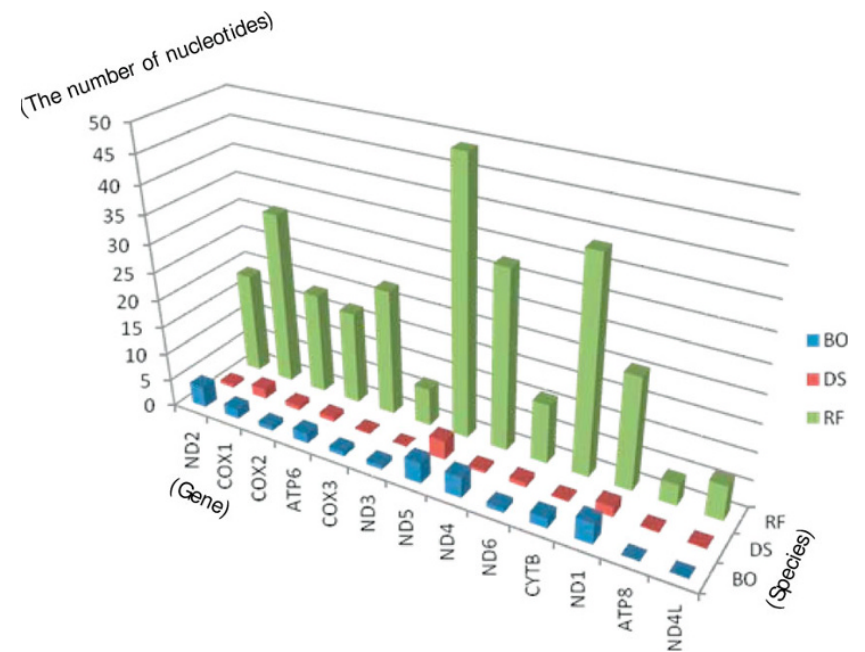

Figure 4

Distribution of SNPs in 13 PCGs in 9 mitochondrial genomes. The bar graph displays the distribution of SNPs in I 3 PCGs of three insect species: BO, Bactrocera oleae; DS, Drosophila simulans; RF, Reticulitermes flavipes. ATP6 and 8 (ATP synthase subunit 6 and 8); COXI-3 (cytochrome c oxidase subunits I-III); CYTB (cytochrome b); NDI-6 (NADH dehydrogenase subunits I-6); ND4L (NADH dehydrogenase subunit 4L) (see also Table 4).

under a selected node in the resulting phylogenetic tree by clicking the node is also provided.

\section{Comparative mitochondrial genomics via the SNU Genome Browser}

To support intuitive visualization of sequences, SNPs, and INDELs between two mitochondrial genomes, the
SNU Genome Browser (http://genomebrowser.snu.ac.kr/) [25] was implemented. This recently developed genome browser provides an interactive user interface that supports visualization of the alignment region between genomes with the capability of comparing multiple genomes simultaneously (Figure 7). It also supports the text browser function for displaying nucleotide sequences of a selected region, supporting the confirmation of SNPs and INDELs. The table browser provides a list of individual elements present in the selected region with their positional information in a tabular form.

\section{Favorite, a personalized virtual space for storing data and conducting further analysis}

Most of the data analysis and/or retrieval interfaces in IMGD provide the Object Browser, which allows users to save all or selected sequences and/or species shown into Favorite. This will help users manage their own datasets via IMGD. Through the interface of Favorite, BLAST, six different phylogenetics programs, and four data analysis tools are available for further analyses (Figure 8). The Favorite is linked to CFGP (http://cfgp.snu.ac.kr/), which provides not only diverse bioinformatic tools but also a data warehouse containing complete sequences of 19 insect nuclear genomes [24], so that further analyses with diverse resources can be conducted easily via this web interface.

\section{Conclusion}

We developed IMGD to support versatile comparative analyses of hexapod mitochondrial gene/genome sequences. In IMGD, 132 completely or nearly-completely sequenced mitochondrial genomes and 113,985 mitochondrial gene sequences from 25,747 species were archived. The IMGD provides a variety of phylogenetic 


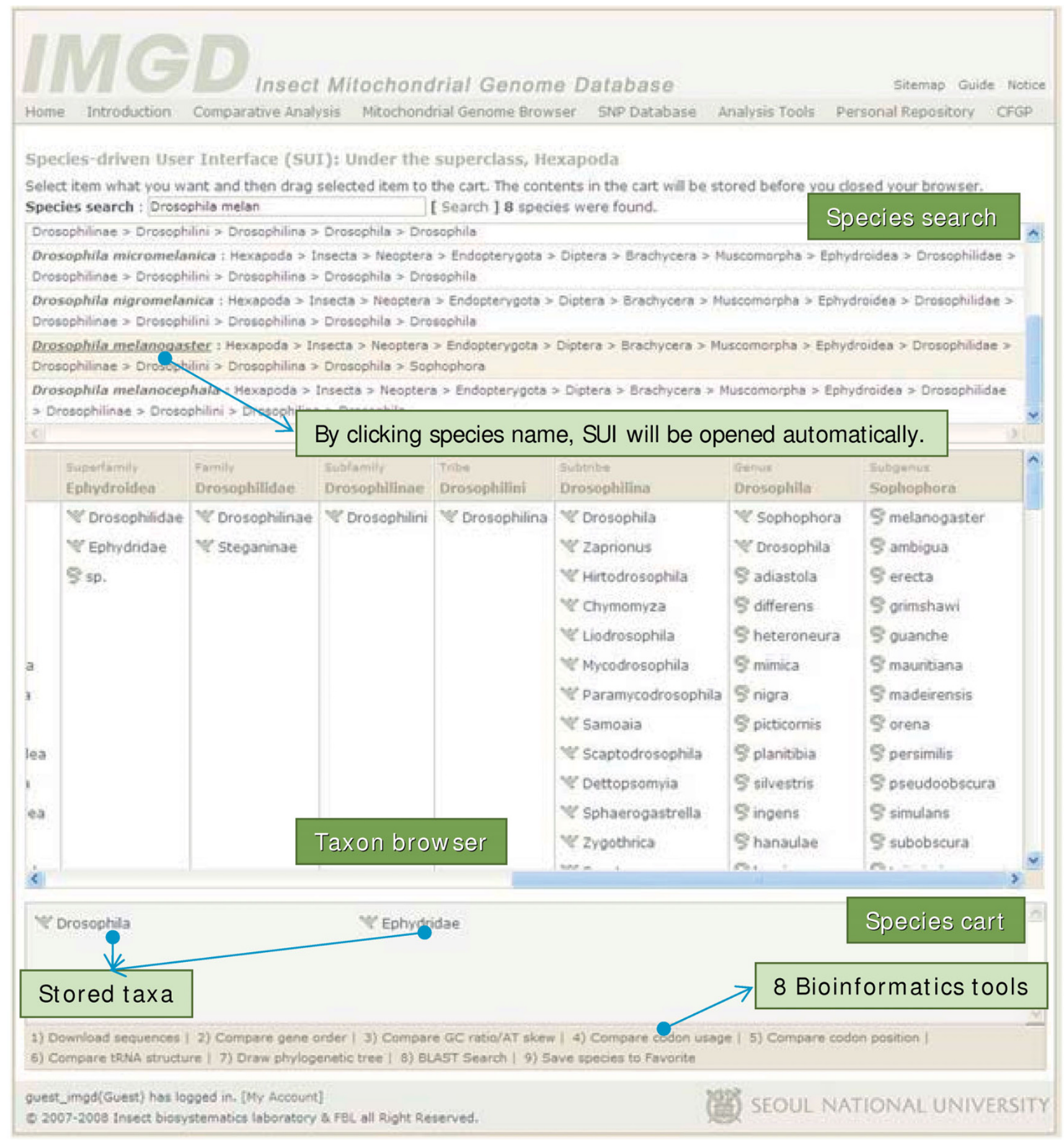

\section{Figure 5}

Species-driven User Interface (SUI) optimized for collecting data based on taxa. The Species-driven User Interface (SUI) consists of three parts: i) Species search, ii) Taxon browser, and iii) Species cart. The Species search function supports the search of species by species name. The Taxon browser provides the interface for browsing taxa in a hierarchical manner. The Species cart can store selected taxa, bridging the data from them to nine bioinformatics tools. 


\section{Analysis Tools}

Gene Order Browser

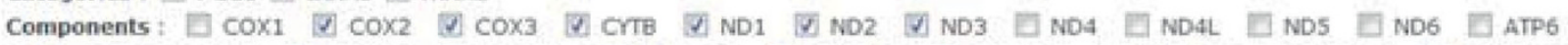

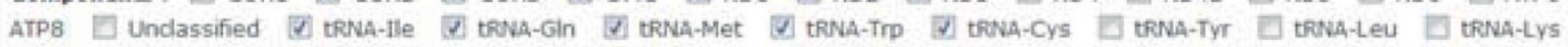

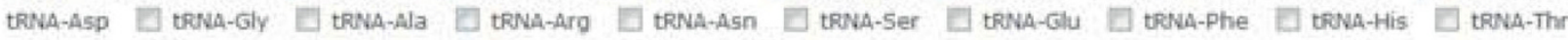

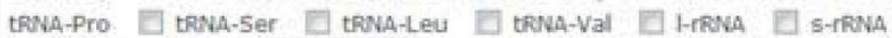
Standard to display $=\operatorname{cox} 2$.

[ Apply Options ]

\section{Gene order diagram}

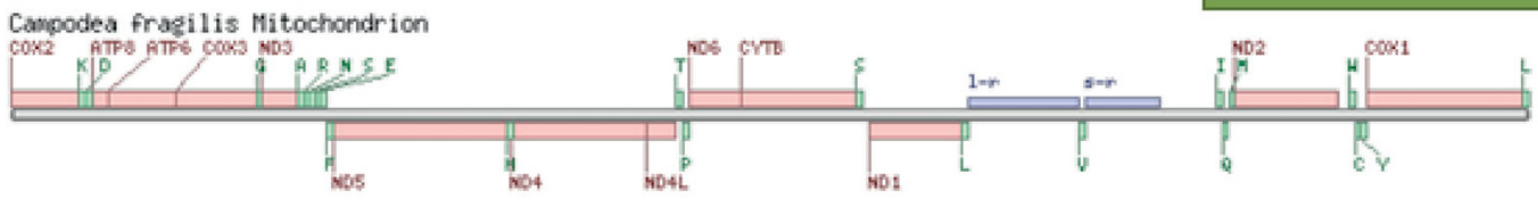

Japyx solifugis Mitochondrion

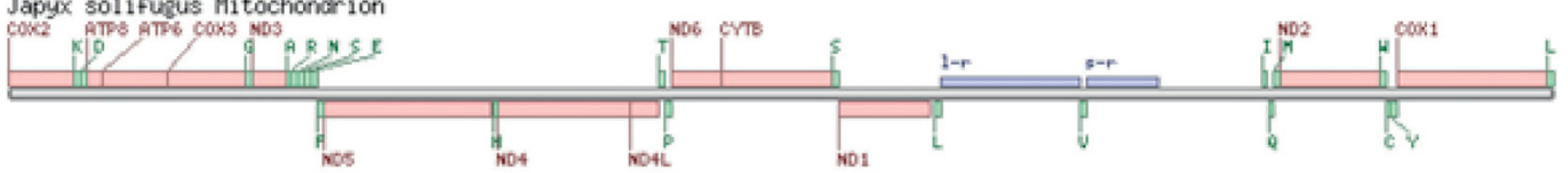

Petrobius brevistylis Mitochondrion
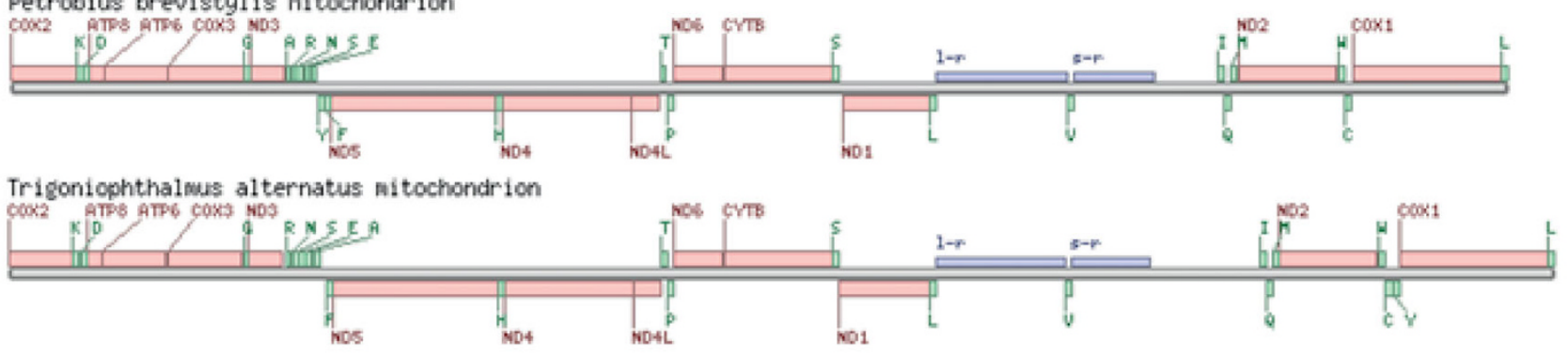

\section{Figure 6}

Gene order browser for graphical presentation of the mitochondrial gene order. The gene order browser consists of two parts: one is the option window and the other is the gene order diagram. In the option window, three options, including width, categories, and components, are displayed. After clicking 'Apply Options,' a gene order diagram based on the chosen option will be displayed. To indicate the nature of specific genetic elements on displayed mitochondrial genomes, the following abbreviations were used: A, tRNA-Ala;C, tRNA-Cys; D, tRNA-Asp; E, tRNA-Glu; F, tRNA-Phe; G, tRNA-Gly; H, tRNA-His; I, tRNA-Ile; K, tRNA-Lys; L, tRNA-Leu; M, tRNA-Met; N, tRNA-Asn; P, tRNA-Pro; Q, tRNA-GIn; R, tRNA-Arg; S, tRNA-Ser; T, tRNA-Thr; V, tRNA-Val; W, tRNA-Trp; Y, tRNA-Tyr; COXI-3, cytochrome c oxidase subunits I-III; CYTB, cytochrome b; ATP6 and ATP8, subunits 6 and 8 of the FoATPase; NDI-6 and nad4L, NADH dehydrogenase subunits I-6 and 4L; I-r and s-r, large and small subunit of ribosomal RNA genes; PCGs, protein coding genes; rRNAs, ribosomal RNA genes; tRNAs, transfer RNA genes.

analysis tools via Phyloviewer, which supports the interactive graphical presentation of resultant phylogenetic trees. The IMGD, supported by the SNP analysis platform and the SNU Genome Browser, provides a graphical view of mitochondrial genome comparisons. In the near future, additional analysis tools, such as PAML [50] for the determination of positive/negative selection based on $\mathrm{dS} / \mathrm{dN}$ values, will be integrated into IMGD. Moreover, based on the database of widely sequenced mitochondrial genes, an insect species identification system based on multiple loci can be developed. The IMGD is expected to significantly enhance evolutionary studies on the superclass Hexapoda using rapidly accumulating insect mitochondrial genome sequences. 
Drosophila simulans KY007 Mitochondrion

AY518670 (Total Length : 14,946bp)

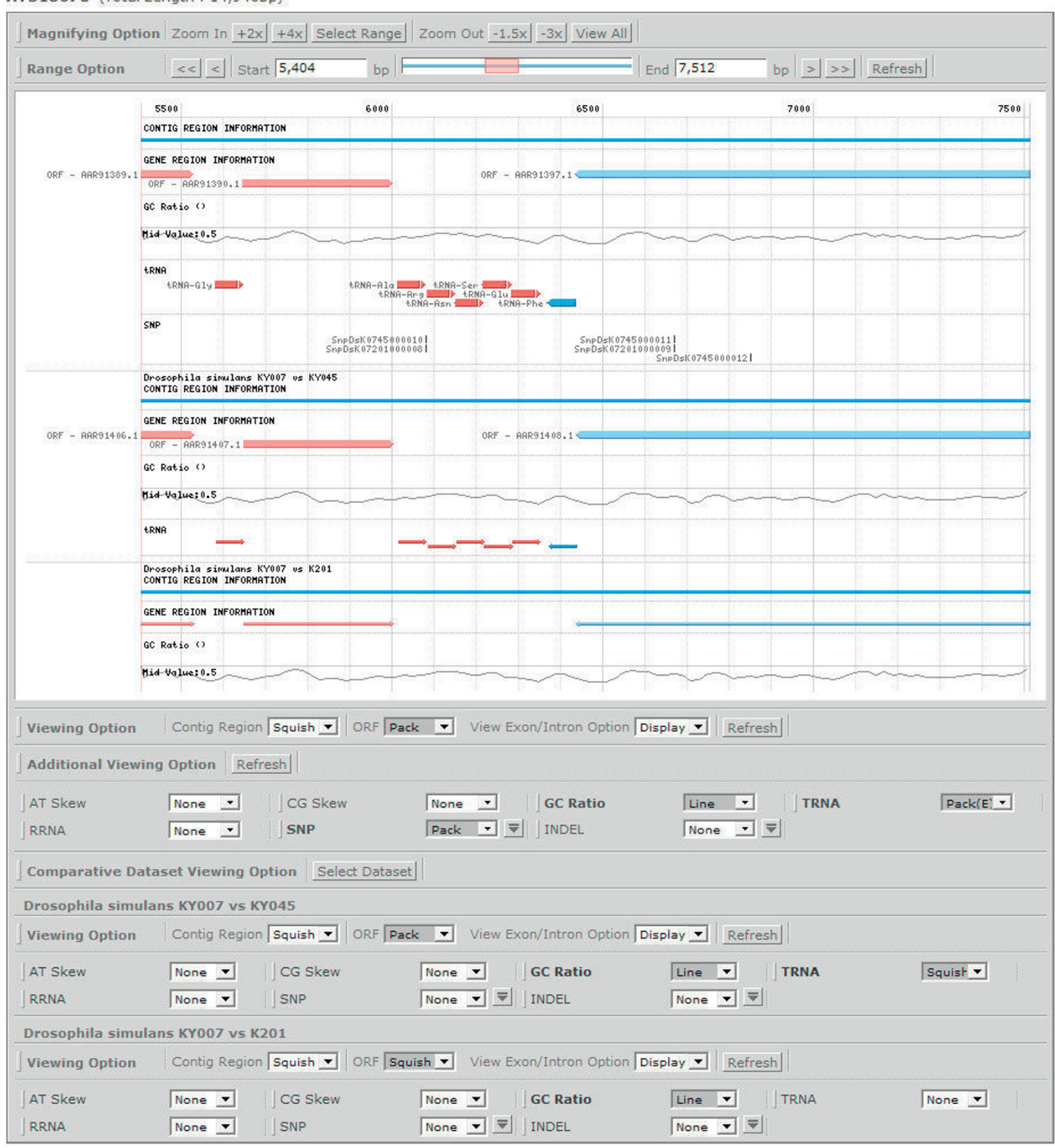

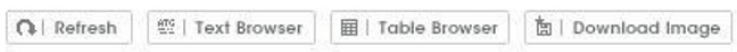

Figure 7

Interactive graphical interface for visualizing aligned mitochondrial genomes via the SNU Genome Browser. The SNU Genome Browser displays SNPs/INDELs as well as PCGs, tRNAs, GC contents among the aligned genomes of Drosophila simulans KY007, KY045, and K20I strains. 


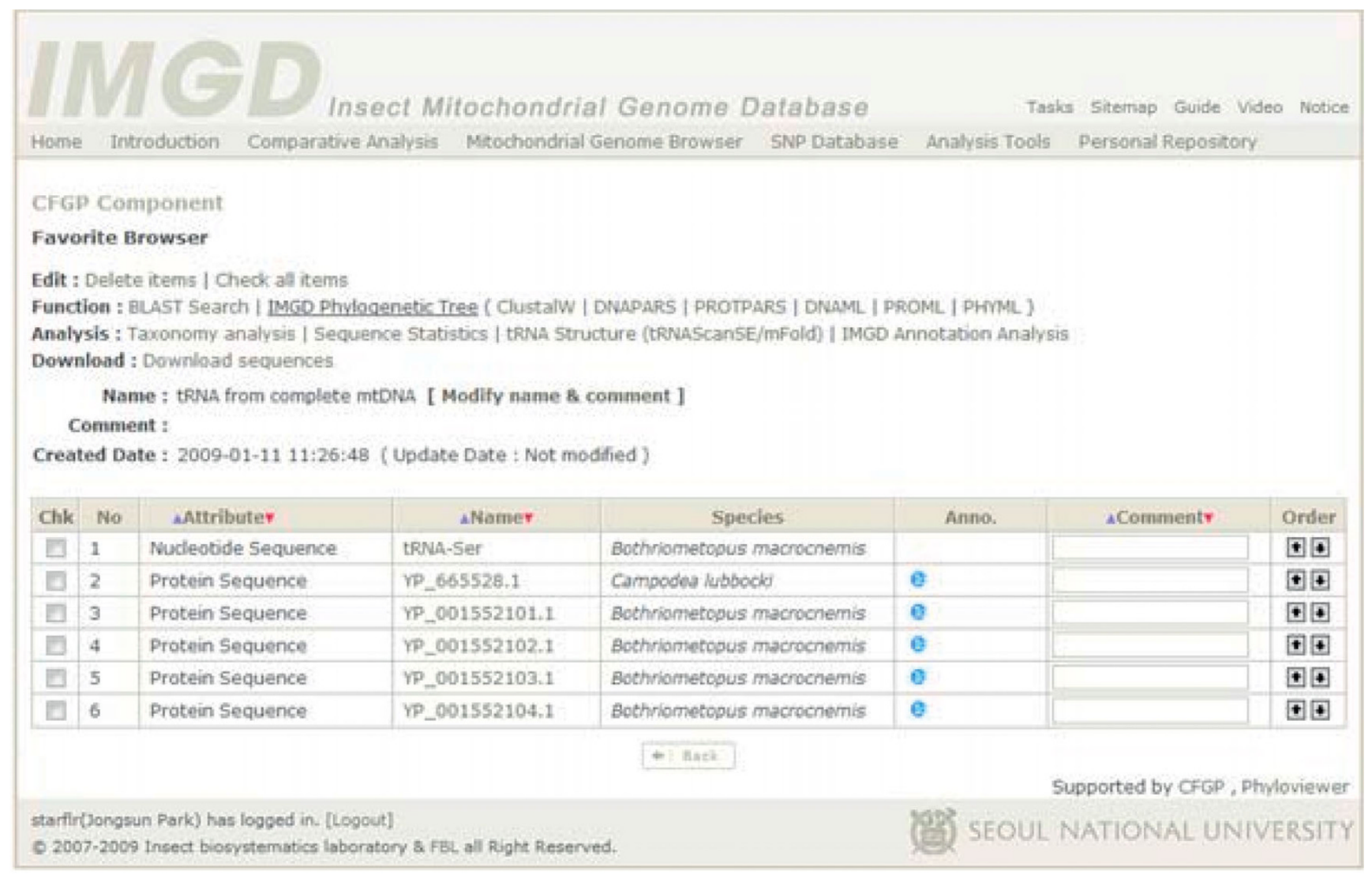

\section{Figure 8}

Favorite, a personalized virtual space for data storage and further analyses. The browser in Favorite provides four options: 'Edit,' 'Function,' 'Analysis,' and 'Download.' Any sequences listed at the bottom part can be selected by users for analyzing the selected sequences using seven programs and four analysis tools via the web.

\section{Availability and requirements}

All data described in this paper can be browsed and downloaded through the IMGD web site at http://www. imgd.org/.

\section{Authors' contributions}

$\mathrm{WL}, \mathrm{JP}, \mathrm{SL}$, and YHL designed and managed this project, JC, JP, and WL construct the IMGD sequence database and $\mathrm{WL}, \mathrm{JL}, \mathrm{JC}$, and JP curated all sequences in IMGD. KJ designed the IMGD web site and developed SUI. BP developed the interface for Phyloviewer, JP integrated SAP to IMGD and DH conducted mitochondrial genome alignments. JP, JC, BP, KJ, KA, DH and WS constructed and tested the whole web pages. WL, JP and SK wrote the manuscript.

\section{Acknowledgements}

This research was supported by Korea Ministry of Environment as "The Eco-technopia 2I project", a grant from by Agricultural R\&D Promotion Center, and a grant from Biogreen2I Project (2007030 1034032) to S.L. It was also supported by a grant from Crop Functional Genomics Center (CGII4I), Korean Research Foundation Grant (KRF-2006-005-J0470I), Biogreen2I Project (2008040I034044) funded by Rural Development Administration and the Korea Science and Engineering Foundation (KOSEF) grant funded by the Korea government (MEST) (RII-2008062-0300I-0) to Y.H.L. J.P. acknowledges a graduate fellowship provided by the Ministry of Education through the Brain Korea 2I Project.

\section{References}

I. Rawlings TA, Collins TM and Bieler R: A major mitochondrial gene rearrangement among closely related species. Mol Biol Evol 200I, I8(8):1604-1609.

2. Dowton M: Relationships among the cyclostome braconid (Hymenoptera: Braconidae) subfamilies inferred from a mitochondrial tRNA gene rearrangement. Mol Phylogenet Evol 1999, I I(2):283-287.

3. Boore JL: Animal mitochondrial genomes. Nucleic Acids Res 1999, 27(8): 1767-1780.

4. Boore $\mathrm{JL}$ and Brown WM: Big trees from little genomes: mitochondrial gene order as a phylogenetic tool. Curr Opin Genet Dev 1998, 8(6):668-674.

5. Boore JL, Lavrov DV and Brown WM: Gene translocation links insects and crustaceans. Nature 1998, 392(6677):667-668.

6. Ellegren H: Sequencing goes 454 and takes large-scale genomics into the wild. Mol Ecol 2008, I7(7):|629-|63|. 
7. Jameson D, Gibson AP, Hudelot C and Higgs PG: OGRe: a relational database for comparative analysis of mitochondrial genomes. Nucleic Acids Res 2003, 3 I (I):202-206.

8. Lee YS, Oh J, Kim YU, Kim N, Yang S and Hwang UW: Mitome: dynamic and interactive database for comparative mitochondrial genomics in metazoan animals. Nucleic Acids Res 2008, 36:D938-942.

9. O'Brien EA, Zhang Y, Yang L, Wang E, Marie V, Lang BF and Burger G: GOBASE-a database of organelle and bacterial genome information. Nucleic Acids Res 2006, 34:D697-699.

10. Feijao PC, Neiva LS, de Azeredo-Espin AM and Lessinger AC: AMiGA: the arthropodan mitochondrial genomes accessible database. Bioinformatics 2006, 22(7):902-903.

II. Vasconcelos AT, Guimaraes AC, Castelletti CH, Caruso CS, Ribeiro C, Yokaichiya F, Armoa GR, Pereira Gda S, da Silva IT, Schrago CG, Fernandes AL, da Silveira AR, Carneiro AG, Carvalho BM, Viana CJ, Gramkow D, Lima FJ, Correa LG, Mudado Mde A, Nehab-Hess P, Souza R, Correa RL and Russo CA: MamMiBase: a mitochondrial genome database for mammalian phylogenetic studies. Bioinformatics 2005, 2 I (I0):2566-2567.

12. Wolfsberg TG, Schafer S, Tatusov RL and Tatusov TA: Organelle genome resource at NCBI. Trends Biochem Sci 200I, 26 (3): 199-203.

13. Boykin LM, Shatters RG Jr, Rosell RC, McKenzie CL, Bagnall RA, De Barro P and Frohlich DR: Global relationships of Bemisia tabaci (Hemiptera: Aleyrodidae) revealed using Bayesian analysis of mitochondrial COI DNA sequences. Mol Phylogenet Evol 2007, 44(3): $1306-1319$

14. Morlais I and Severson DW: Complete mitochondrial DNA sequence and amino acid analysis of the cytochrome C oxidase subunit I (COI) from Aedes aegypti. DNA Seq 2002, I3 (2): $123-127$

15. Waeschenbach A, Telford MJ, Porter JS and Littlewood DT: The complete mitochondrial genome of Flustrellidra hispida and the phylogenetic position of Bryozoa among the Metazoa. Mol Phylogenet Evol 2006, 40(I): I95-207.

16. Kress WJ and Erickson DL: DNA barcodes: genes, genomics, and bioinformatics. Proc Natl Acad Sci USA 2008, I 05 (8):276I-2762.

17. Ratasingham S and Hebert PDN: BOLD: The Barcode of Life Data System http://www.barcodinglife.org. Mol Ecol Notes 2007, 7(3):355-364.

18. Hajibabaei M, Janzen DH, Burns JM, Hallwachs W and Hebert PD: DNA barcodes distinguish species of tropical Lepidoptera. Proc Natl Acad Sci USA 2006, I03(4):968-97I.

19. Stahls G and Savolainen E: MtDNA COI barcodes reveal cryptic diversity in the Baetis vernus group (Ephemeroptera, Baetidae). Mol Phylogenet Evol 2008, 46(I):82-87.

20. Pfenninger M, Nowak C, Kley C, Steinke D and Streit B: Utility of DNA taxonomy and barcoding for the inference of larval community structure in morphologically cryptic Chironomus (Diptera) species. Mol Ecol 2007, I 6(9): 1957-1968.

21. Nelson LA, Wallman JF and Dowton M: Using COI barcodes to identify forensically and medically important blowflies. Med Vet Entomol 2007, 2 I(I):44-52.

22. Roe AD and Sperling FA: Patterns of evolution of mitochondrial cytochrome c oxidase I and II DNA and implications for DNA barcoding. Mol Phylogenet Evol 2007, 44(I):325-345.

23. Caterino MS, Cho $S$ and Sperling FA: The current state of insect molecular systematics: a thriving Tower of Babel. Annu Rev Entomol 2000, 45: I-54.

24. Park J, Park B, Jung K, Jang S, Yu K, Choi J, Kong S, Park J, Kim S, Kim H, Kim S, Kim J, Blair J, Lee K, Kang S and Lee Y-H-: CFGP: A Web-based, Comparative Fungal Genomics Platform. Nucleic Acids Res 2008, 36:D562-D571.

25. Jung K, Park J, Choi J, Park B, Kim S, Ahn K, Choi J, Choi D, Kang S and Lee $Y-H$ : SNUGB: a versatile genome browser supporting comparative and functional fungal genomics. BMC Genomics 2008, 9:585

26. McGinnis S and Madden TL: BLAST: at the core of a powerful and diverse set of sequence analysis tools. Nucleic Acids Res 2004, 32:W20-25.

27. Lowe TM and Eddy SR: tRNAscan-SE: a program for improved detection of transfer RNA genes in genomic sequence. Nucleic Acids Res 1997, 25(5):955-964.

28. Zuker M: Mfold web server for nucleic acid folding and hybridization prediction. Nucleic Acids Res 2003, 3 I (I3):3406-34I5.
29. Felsenstein J: PHYLIP (PHYLogeny Inference Package).Seattle: Distributed by the author, Department of Genetics, University of Washington, Seattle, WA; 3.6a21993.

30. Thompson JD, Higgins DG and Gibson TJ: CLUSTAL W: improving the sensitivity of progressive multiple sequence alignment through sequence weighting, position-specific gap penalties and weight matrix choice. Nucleic Acids Res 1994, 22 (22): $4673-4680$

31. Guindon S, Lethiec F, Duroux P and Gascuel O: PHYML Online-a web server for fast maximum likelihood-based phylogenetic inference. Nucleic Acids Res 2005, 33:W557-559.

32. Choi J, Park J, Jeon J, Chi MH, Goh J, Yoo SY, Park J, Jung K, Kim H, Park SY, Rho HS, Kim S, Kim BR, Han SS, Kang S and Lee YH: Genome-wide analysis of T-DNA integration into the chromosomes of Magnaporthe oryzae. Molecular Microbiology 2007, 66(2):37I-382.

33. Jeon J, Park SY, Chi MH, Choi J, Park J, Rho HS, Kim S, Goh J, Yoo S, Choi J, Park JY, Yi M, Yang S, Kwon MJ, Han SS, Kim BR, Khang CH, Park B, Lim SE, Jung K, Kong S, Karunakaran M, Oh HS, Kim H, Kim S, Park J, Kang S, Choi WB, Kang S and Lee YH: Genome-wide functional analysis of pathogenicity genes in the rice blast fungus. Nat Genet 2007, 39(4):56I-565.

34. Park J, Park B, Veeraraghavan N, Jung K, Lee YH, Blair J, Geiser DM, Isard S, Mansfield MA, Nikolaeva E, Park SY, Russo J, Kim SH, Greene M, Ivors KL, Balci Y, Peiman M, Erwin DC, Coffey MD, Rossman A, Farr D, Cline E, Crünwald NJ, Luster DG, Schrandt J, Martin F, Ribeiro OK, Makalowska I and Kang S: Phytophthora Database: A Forensic Database Supporting the Identification and Monitoring of Phytophthora. Plant Dis 2008, 92 (6):966-972.

35. Park J, Park J, Jang S, Kim S, Kong S, Choi J, Ahn K, Kim J, Lee S, Kim S, Park B, Jung K, Kim S, Kang S and Lee YH: FTFD: An Informatics Pipeline Supporting Phylogenomic Analysis of Fungal Transcription Factors. Bioinformatics 2008, 24 (7): 1024-1025.

36. Park J, Lee S, Choi J, Ahn K, Park B, Park J, Kang S and Lee YH: Fungal Cytochrome P450 Database. BMC Genomics 2008, 9 (I):402.

37. Xi H, Park J, Ding G, Lee YH and Li Y: SysPIMP: the web-based systematical platform for identifying human disease-related mutated sequences from mass spectrometry. Nucleic Acids Res 2008, 37:D913-D920.

38. Hong MY, Lee EM, Jo YH, Park HC, Kim SR, Hwang JS, Jin BR, Kang PD, Kim KG, Han YS and Kim I: Complete nucleotide sequence and organization of the mitogenome of the silk moth Caligula boisduvalii (Lepidoptera: Saturniidae) and comparison with other lepidopteran insects. Gene 2008, 413 (I-2):49-57.

39. Sheffield NC, Song H, Cameron SL and Whiting MF: A comparative analysis of mitochondrial genomes in Coleoptera (Arthropoda: Insecta) and genome descriptions of six new beetles. Mol Biol Evol 2008, 25 (I I):2499-2509.

40. Cameron SL, Lambkin CL, Barker SC and Whiting MF: A mitochondrial genome phylogeny of Diptera: whole genome sequence data accurately resolve relationships over broad timescales with high precision. Syst Entomol 2007, 32(I):40-59.

41. Boore JL, Collins TM, Stanton D, Daehler LL and Brown WM: Deducing the pattern of arthropod phylogeny from mitochondrial DNA rearrangements. Nature 1995, 376 (6536): I63-165.

42. Johnson KP and Whiting MF: Multiple genes and the monophyly of Ischnocera (Insecta: Phthiraptera). Mol Phylogenet Evol 2002, 22(I): $101-110$

43. Johnson KP, Cruickshank RH, Adams RJ, Smith VS, Page RD and Clayton DH: Dramatically elevated rate of mitochondrial substitution in lice (Insecta: Phthiraptera). Mol Phylogenet Evol 2003, 26(2):231-242.

44. Price RD and Johnson KP: Four new species of Myrsidea Waterston chewing lice (Phthiraptera: Menoponidae) from the Malagasy warblers (Passeriformes). Zootaxa 2006, 1 297:47-55.

45. Klass K-D, Picker MD, Damgaard J, van Noort S and Tojo K: The Taxonomy, Genitalic Morphology, and Phylogenetic Relationships of South African Mantophasmatodea (Insecta). Entomol Abh 2003, 6 I (I):3-67

46. Damgaard J, Klass KD, Picker MD and Buder G: Phylogeny of the Heelwalkers (Insecta: Mantophasmatodea) based on mtDNA sequences, with evidence for additional taxa in South Africa. Mol Phylogenet Evol 2008, 47(2):443-462. 
47. Cameron SL and Whiting MF: Mitochondrial genomic comparisons of the subterranean termites from the Genus Reticulitermes (Insecta: Isoptera: Rhinotermitidae). Genome 2007, 50(2): 188-202.

48. Yukuhiro K, Sezutsu H, Itoh M, Shimizu K and Banno Y: Significant levels of sequence divergence and gene rearrangements have occurred between the mitochondrial genomes of the wild mulberry silkmoth, Bombyx mandarina, and its close relative, the domesticated silkmoth, Bombyx mori. Mol Biol Evol 2002, 19(8): I385-1389.

49. Solignac M: Mitochondrial DNA in the Drosophila melanogaster complex. Genetica 2004, I 20(I-3):4|-50.

50. Yang Z: PAML 4: phylogenetic analysis by maximum likelihood. Mol Biol Evol 2007, 24(8): I586-I59I.

Publish with BioMed Central and every scientist can read your work free of charge

"BioMed Central will be the most significant development for disseminating the results of biomedical research in our lifetime. "

Sir Paul Nurse, Cancer Research UK

Your research papers will be:

- available free of charge to the entire biomedical community

- peer reviewed and published immediately upon acceptance

- cited in PubMed and archived on PubMed Central

- yours - you keep the copyright

Submit your manuscript here:

http://www.biomedcentral.com/info/publishing_adv.asp
BioMedcentral 